\title{
The design and development of a hybrid off-job crafting intervention to enhance needs satisfaction, well-being and performance: a study protocol for a randomized controlled trial
}

\author{
Merly K. Kosenkranius ${ }^{1 *}$ (D) Floor A. Rink ${ }^{1}$, Jessica de Bloom ${ }^{1,2}$ and Machteld van den Heuvel ${ }^{3}$
}

\begin{abstract}
Background: Employees dealing with job demands such as high workload and permeable work-life boundaries could benefit from bottom-up well-being strategies such as off-job crafting. We have developed a hybrid off-job crafting intervention to promote off-job crafting, a proactive pursuit to adjust one's off-job time activities to satisfy one's psychological needs. This hybrid intervention contains both on-site (two trainings) and online elements (smartphone app) to enhance employees' well-being and performance within different life domains.

Methods: The study is designed as a randomized controlled trial with an intervention group and a waitlist control group. The study population will be Finnish knowledge workers. The intervention program focuses on six psychological needs (detachment, relaxation, autonomy, mastery, meaning, and affiliation) proposed by the DRAMMA model. The intervention will consist of the following components: 1) an on-site off-job crafting training, 2) an individual off-job crafting plan for the four-week intervention period, 3) Everydaily smartphone app usage, and 4) a training session for reflection. The study outcomes are assessed with online questionnaires once at baseline, weekly during the intervention period and twice after the intervention (two-week and six-week follow-up). Moreover, during the second training session, participants will participate in a process evaluation to shed light on the mechanisms that can affect the effectiveness of the intervention.

Discussion: We expect that the intervention will stimulate off-job crafting behaviors, which may in turn increase well-being and performance in both non-work and work domains during and after the intervention (compared to baseline and to the control group). The intervention may provide employees with additional resources to deal with various stressors in life. Furthermore, this off-job crafting intervention could also offer performance benefits for the employers such as increased organizational citizenship behaviors among employees.
\end{abstract}

Trial registration: The Netherlands Trial Register (NTR): NL8219, December 9, 2019. Registered retrospectively. https://www.trialregister.nl/trial/8219

Keywords: Off-job crafting, Psychological needs, Well-being, Job performance, M-health

\footnotetext{
* Correspondence: m.k.kosenkranius@rug.nl

'Department of HRM \& OB, Faculty of Economics and Business, University of

Groningen, Nettelbosje 2, 9747, AE, Groningen, the Netherlands

Full list of author information is available at the end of the article
}

(c) The Author(s). 2020 Open Access This article is distributed under the terms of the Creative Commons Attribution 4.0 International License (http://creativecommons.org/licenses/by/4.0/), which permits unrestricted use, distribution, and reproduction in any medium, provided you give appropriate credit to the original author(s) and the source, provide a link to the Creative Commons license, and indicate if changes were made. The Creative Commons Public Domain Dedication waiver (http://creativecommons.org/publicdomain/zero/1.0/) applies to the data made available in this article, unless otherwise stated. 


\section{Background}

Demographic and economic changes have increased the need for employees to stay in the workforce longer than before, while also retaining high well-being and productivity. At the same time, the current workforce has to deal with job demands such as high workload and permeable work-life boundaries [1]. Excessive job demands can turn into stressors, which over time can lead to serious health outcomes, such as exhaustion [2]. This, in turn, can lead to negative consequences on the organizational level, such as increased absenteeism rates [3].

Scholars have proposed that employees dealing with high job demands could benefit from bottom-up wellbeing approaches $[4,5]$. One of such approaches is job crafting, which refers to proactively adjusting one's level of job demands and resources at work [6]. Although research has demonstrated that proactively adjusting one's work activities to satisfy psychological needs can help employees to achieve higher well-being at work [7], limited research exists on the benefits of proactively adjusting one's off-job time activities to satisfy psychological needs during non-work time, referred to as off-job crafting.

Within non-work domain, leisure crafting was first proposed as a concept different from mere participation in leisure activities [8], and later defined as "the proactive pursuit and enactment of leisure activities targeted at goal setting, human connection, learning and personal development" [9]. As people might engage in both recreational activities (e.g., sports, hobbies), and other nonwork time activities (e.g., childcare, domestic tasks, volunteer work) to satisfy their psychological needs during the time they are not working, we refer to this form of crafting as off-job crafting. Off-job crafting may help to recover from stressful work because the demands on person's psychophysiological systems are lower during that time and psychological resources can be replenished [10].

According to self-determination theory [11] all individuals have three innate psychological needs: autonomy, competence, and relatedness. Humans who actively seek out opportunities that satisfy these psychological needs will, in turn, experience positive psychological outcomes such as higher well-being [11] and performance [12]. More recently, Newman, Tay, and Diener [13] proposed a model of six psychological mechanisms mediating the relationship between leisure and subjective well-being. According to the DRAMMA model, these six psychological needs are: detachment, relaxation (referred to as "recovery" in the original model), autonomy, mastery, meaning, and affiliation. Detachment is characterized by mentally disengaging from work-related matters, while relaxation refers to low levels of mental or physical activation and little physical or intellectual effort [14]. Autonomy, one of the basic psychological needs proposed by Ryan and Deci [15], is the desire to experience ownership of one's behavior. Mastery involves seeking learning opportunities and optimal challenges to experience feelings of achievement and competence [14]. Meaning refers to engaging in activities that individuals perceive as opportunities to gain something valuable in life [16]. Affiliation is the desire to experience relatedness and belongingness with other people [15].

Off-job crafting is primarily expected to satisfy psychological needs in non-work related life domains, but due to the universal nature of people's basic psychological needs, it should also generate indirect spillover effects on work-related well-being and performance [17]. As there are significantly less -or even no- interfering job demands present during non-work time, people should be more effective in rebuilding their psychological resources via off-job crafting. This could ultimately also benefit people at work. We therefore propose that offjob crafting enhances employees' well-being and performance both within the non-work domain as well as across life domains by the regeneration of psychological resources and satisfaction of psychological needs. To date and to the best of our knowledge, however, interventions to study whether off-job crafting yields these anticipated effects in terms of both well-being and performance in both life domains do not yet exist. We have therefore designed a hybrid off-job crafting intervention to stimulate off-job crafting among employees to enhance their psychological need satisfaction, well-being, and performance.

The aim of this intervention study is to evaluate the effectiveness of a hybrid off-job crafting intervention compared to a waitlist control group on off-job crafting behaviors, psychological need satisfaction, well-being and performance. We hypothesize that off-job crafting can be stimulated in the intervention group compared to a waitlist control group (between-person difference), and that people will engage more often in off-job crafting during and after the intervention period than before (within-person changes). Moreover, we expect that increased off-job crafting will lead to higher well-being and performance during and after the intervention (compared to baseline and to the control group). We hypothesize that as the result of the intervention, participants will report higher basic need satisfaction and satisfaction of psychological needs during and after the intervention compared to baseline and to the waitlist control group. In terms of work-related well-being outcomes, we expect that participants will report higher work engagement and job satisfaction during and after the intervention compared to baseline and to the waitlist control group. In the non-work domain, we hypothesize 
that participants will report higher subjective vitality, private life satisfaction and health status and lower stress and mental fatigue levels during and after the intervention compared to baseline and to the waitlist control group. We also expect the intervention to have a positive effect on both work-related and non-work performance. Namely, we expect participants to report higher job performance and organizational citizenship behavior at work and increased family role performance in the non-work domain during and after the intervention compared to baseline and to the waitlist control group. Additionally, we will explore, whether variables such as proactive personality, focus on opportunities, selection, optimization, and compensation strategies, need strengths, home and job demands, job crafting and off-job time activities have a role in participants' engagement in different off-job crafting behaviors and its effects to their well-being and performance in different life domains.

The intervention development is partly based on the Intervention Mapping approach [18] which provides a stepwise process for developing evidence-based health promotion interventions. As a starting point, the planning group, consisting of researchers and well-being trainers, explored the needs and necessity of managing work-life balance and optimizing the use of leisure time, both theoretically and practically in the Finnish context. Recent studies $[19,20]$ have demonstrated that Finnish workers with knowledge-intensive jobs have difficulties to manage boundaries between work and non-work time. The advancements in mobile technology have made it possible for the employees to choose their work time and place. A study by Ropponen and colleagues [19] demonstrated that majority (79\%) of employees felt the need to be available for the work all the time. According to the study conducted by Toivanen and colleagues [20], $42 \%$ of employees reported that they think about job-related matters often or rather often at home and only less than third reported feeling that they are well-recovered from work-related stress. Moreover, nonwork time itself can also present people with different type of demands. Salmela-Aro and Upadyaya [21] showed that personal demands such as economic problems and taking care of dependents (e.g., children, elderly parents) vary across the lifespan of Finnish employees and are associated to work burnout. Based on the needs assessment, the following program objectives were formulated: increasing employees' awareness of their psychological needs, and demands and resources both at work and in personal life; increasing awareness of off-job crafting possibilities; and stimulating off-job crafting behaviors among employees (including during breaks at work). We adapted the design of an existing job crafting intervention [22] to achieve these objectives. As part of the off-job crafting intervention, participants will (1) participate in two on-site trainings, (2) follow a self-composed off-job crafting plan, and (3) use the Everydaily smartphone app. The materials were pretested with a small group of students and adjusted based on their feedback. Before delivering the intervention, pilot testing of the program materials took place with employees from a target organization.

\section{Methods/design}

\section{Study design}

The effectiveness of the hybrid off-job crafting intervention will be evaluated using a two-armed randomized control trial with an intervention group and a waitlist control group. The study design is presented in Fig. 1 .

The study will be carried out in Finland from October 2019 to May 2020. All participants who have given informed consent to participate in the study will first fill out an online baseline questionnaire, concerning demographics (e.g., age, gender, education), basic job information (e.g., work hours), off-job and job crafting, psychological needs, well-being (e.g., mental fatigue, work engagement) and performance (e.g., family role performance, organizational citizenship behavior) 2 weeks before the intervention period. Additionally, intervention group participants will receive a small task to complete before the first training session. The task consists of composing a list of things that the participant likes and dislikes doing during their off-job time. In addition, they are asked to take two picture that represent: 1) an activity that they loved doing over the past week and 2) an activity that they did not like to do during their off-job time. One week before the first training session, participants will receive a reminder to complete the questionnaire and the homework task. Two weeks after the baseline measurement, intervention group participants will take part in a half-day long training session. Shortly before the training, each intervention group participant receives a personal feedback report containing information about their baseline scores on DRAMMA needs satisfaction and comparison of their scores to reference values derived from other published scientific studies with Finnish and European knowledge workers as the reference group [23-25]. During the fourweek intervention period, every Tuesday, intervention group participants will receive an email with a link to a weekly online questionnaire. In case of non-response, reminders will be sent on Wednesdays and Thursdays. The control group will be asked to fill out a second questionnaire immediately after the end of the intervention period of the intervention group. Additionally, participants from both groups will receive the same online questionnaire via email twice during the post-intervention period (two and six weeks after intervention). After the intervention period, the intervention group will participate in a halfday long reflection session. 


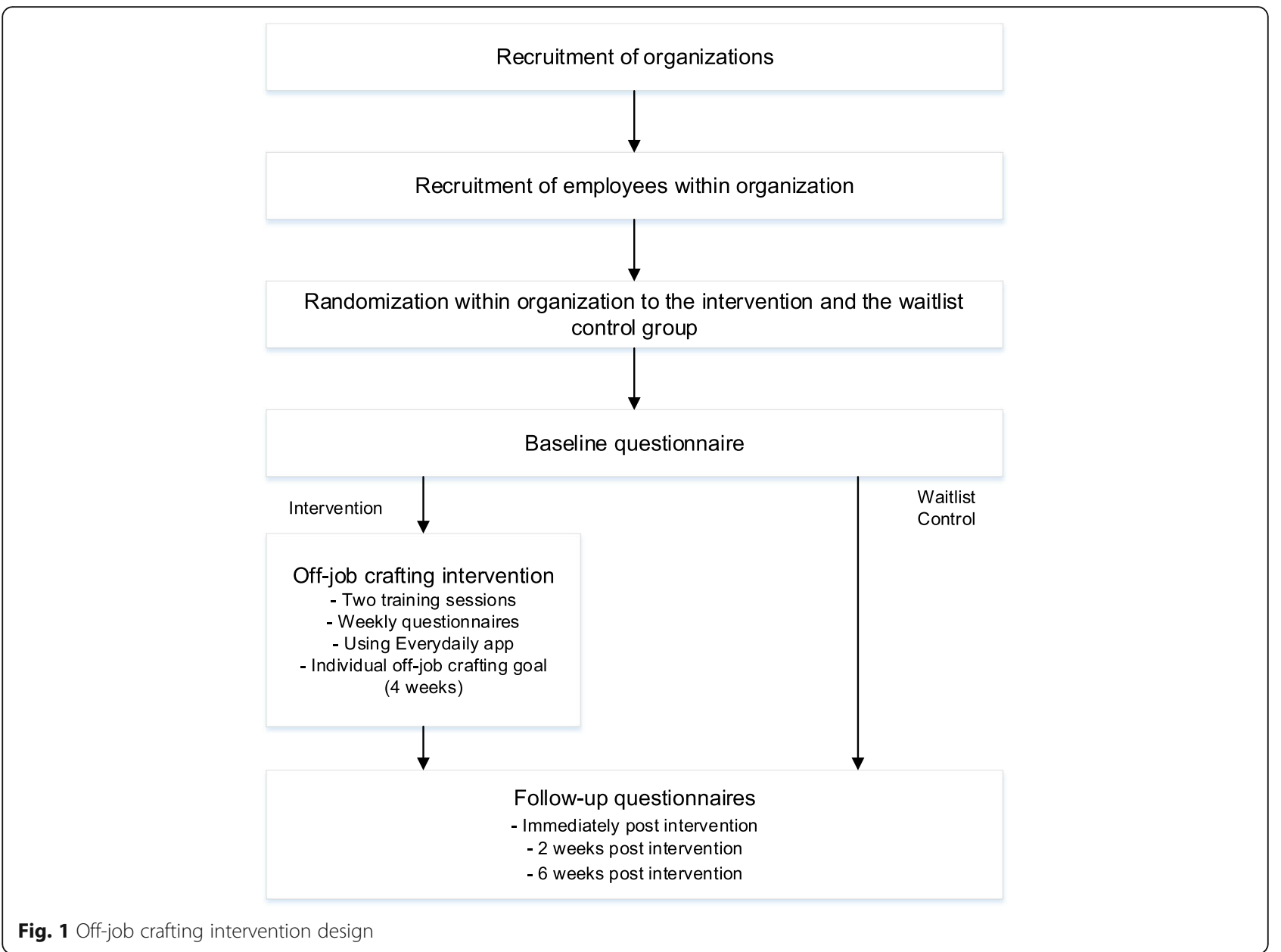

After the intervention, the waitlist control group will be offered a chance to participate in the trainings and all the intervention materials will be made available for them, including the booklet and Everydaily smartphone application.

\section{Study population and recruitment}

The study population is recruited from diverse private and public organizations in the capital region and Pirkanmaa region in Finland. The participants are full-time employees with knowledge-intensive jobs. The contacted organizations have previously been interested in Tampere University recovery studies or belong to the network of the trainers delivering the intervention. We will first contact the organizations' HR representatives by sending them an informational recruitment letter, followed by follow-up calls. Individual informational meetings with interested companies will be arranged.

After the company has agreed to participate in the study, we will forward our recruitment email to their employees. This email includes additional information about the study, including the timeline of the intervention. An organization can take part in the study if there are at least 12 employees interested in participating in the study. In each participating organization, a person will be appointed to facilitate the communication between participants, trainers, and researchers. This person will also provide the employees with a registration form (requesting employee's name and contact information). Within each organization, we aim to assign participants randomly either to the intervention or to the waitlist control group. After the intervention, employers will receive an anonymized group feedback regarding the development of participants' levels of stress, mental fatigue, job performance and organizational citizenship behavior across different measurement points.

\section{Training sessions}

The training sessions take place on site for a maximum of 14 employees at a time. Trainers are experienced occupational well-being coaches trained by the researchers. Additionally, they have been actively involved in the intervention 
development process and are trained in various relaxation methods (e.g., yoga, meditation).

The first training session will focus on introducing the intervention, increasing awareness of stress, psychological needs and off-job crafting, reflecting on personal off-job crafting behaviors in small groups, and developing an individual off-job crafting plan for the intervention period. After a round of introductions, trainers will introduce theoretical findings about stress, off-job crafting and the DRAMMA model. Next, participants will work with their personal feedback reports and homework tasks to reflect on their psychological need satisfaction scores and off-job time activities first individually and then within small groups. The introduction section is followed by several practical exercises.

The practical psychological needs training is divided into six parts, each focusing on a specific DRAMMA need. First, trainers will provide a short theoretical overview of each dimension and a few examples of different strategies found to enhance that specific need. This is followed by a practical exercise addressing the same psychological need. For detachment from work, participants will be asked to think of a transition ritual [26] that would help them to clearly separate their work and nonwork time. To introduce a relaxation strategy, the trainers will conduct a short relaxing stretching exercise. To enhance meaning, participants will engage in a short exercise that helps them to become aware of and act in accordance with their own personal values [27]. For mastery, they will engage in an exercise prompting them to remember a past success experience and to share it with another group member to increase participants' self-efficacy [28]. After the mastery exercise, participants will engage in a strength spotting exercise to enhance affiliation [29]. Participants will take turns in sharing the strengths they have spotted in their colleague based on previously shared success stories to demonstrate how even brief positive interactions can increase the feeling of belonging and positive affect [30]. As participants share a personal story with each other, they get to know each other better and social bonds are strengthened. Finally, to increase autonomy, participants will learn about SMART goal setting [31]. Participants can find all the above described exercises and other training materials in the booklet which they will receive at the beginning of the first training session.

After the psychological needs training, participants will be asked to choose one psychological need that they wish to focus on during the four-week intervention period. While they are free to choose whichever of the six needs they want to work with, we recommend aiming to work with the psychological need that they scored the lowest on. This recommendation is made to support more balanced needs satisfaction across different needs, which has been found to be associated with higher reported well-being [32]. Participants will work in small groups and will be assisted by trainers to come up with their individual SMART off-job crafting goals. In the end, they will write their goals down in their personal booklets. As forming implementation intentions has been shown to improve goal achievement [33], participants will write a postcard for themselves where they outline how implementing their chosen DRAMMA goal will benefit them, what might potentially interfere with achieving the goal and how to overcome these barriers. The postcards will be sent to the participants during the second week of the four-week intervention as a positive reminder to continue working on their goals.

Next, participants will follow an app tutorial outlining the main functions of the smartphone app Everydaily and create their personal off-job crafting projects in the app. At the end of the first training session, trainers will summarize the main points of the training and the next steps, and participants will have a chance to ask questions about both this training session and the intervention in general.

After the four-week intervention period, participants will attend a second half-day training session. During this session, they first fill out the last weekly questionnaire and will receive new individual needs satisfaction scores, which they can compare to their baseline scores. Next, they have a chance to reflect on their experiences by identifying enablers and barriers that affected their off-job crafting during the intervention period. They will then review their previous goals, set future goals, and have the chance to ask questions. Additionally, we will ask participants to fill out a process evaluation questionnaire at the end of the training session to gather information about intervention reach, dose received and participants' attitudes toward the intervention [34].

Both training sessions will include several short 10min breaks between different parts of the training. During these breaks, participants can participate in additional exercises. On the first training day, participants can watch a video of natural surroundings to learn about the restorative effects of nature [35] and do a mindfulness meditation exercise. During the second training session, participants are offered to participate in progressive muscle relaxation exercise [36] and in a mandala coloring session with relaxing music [37].

\section{Everydaily app}

During the first training session, participants will be given individual access codes and instructions for using the Everydaily smartphone app. The app content is specifically developed to present participants with short daily activities (Dailys) to support engagement in off-job crafting behaviors. Participants will create a 4-week 
wellbeing project in the app. Each day, they are presented with three different Dailys, each addressing at least one of the psychological DRAMMA needs (i.e., detachment, relaxation, autonomy, mastery, meaning, affiliation). Participants are encouraged to select and complete Dailys that correspond to the psychological need that they have selected to focus on during the intervention period. Dailys are based on various techniques (e.g., mindfulness meditation, practicing gratitude, goal setting) that target different DRAMMA needs and have been previously shown to improve well-being [38-40]. After participants have completed a Daily, they can upload a picture or short reflection text about the task to the app. Participants' picture and text submissions remain private and will only be visible to themselves. Additionally, they are asked to rate the level of DRAMMA needs fulfillment that they experienced during completing the Daily. Participants can additionally rate their well-being within the app. They can collect points for completing Dailys and can follow their progress in terms of needs satisfaction and well-being on graphs within the app. They are encouraged to use the gamified app throughout the intervention period.

\section{Measures}

All seven questionnaires will include the following constructs: off-job crafting, subjective vitality, mental fatigue, stress, health status, private life satisfaction, job satisfaction, work engagement, family role performance, job performance, organizational citizenship behavior, basic need satisfaction, satisfaction of psychological needs, home demands, job demands and job crafting. Additionally, the baseline questionnaire will include need strengths, proactive personality, focus on opportunities, Selection, Optimization, and Compensation strategies and background variables. Both the baseline and the fourth weekly questionnaire will additionally measure participation in different off-job activities.

\section{Off-job crafting}

Off-job crafting is measured with a new 18-item off-job crafting scale at the baseline and with a shortened 6item version during and after the intervention period [24]. Crafting for each of the six DRAMMA needs is measured by three items at the baseline and one item during and after the intervention period. Example items are: "Over the past week, I've made sure to detach from work-related thoughts during off-job time" (detachment), "Over the past week, I've made sure to experience relaxation of my body and mind during off-job time" (relaxation), "Over the past week, I've planned my off-job activities so that I experience control over my life" (autonomy), "Over the past week, I've organized my off-job activities so that I put my skills, knowledge or abilities into action" (mastery), "Over the past week, I've made sure to experience meaning in my life during off-job time" (meaning), and "Over the past week, I've made sure to experience close connections to the people around me during off-job time" (affiliation). Participants are asked to respond on a 5-point Likert scale $(1=$ never, $5=$ very often).

\section{Well-being \\ Subjective vitality}

Subjective vitality is assessed with four items from the Subjective Vitality Scale [41, 42]. Participants are asked to indicate on a 5-point scale how often they felt alive and vital, energetic, having energy and sprit, and looked forward to each new day over the past week. The response scale ranges from 1 (very rarely or never) to 5 (very often or all the time).

\section{Mental fatigue}

Mental fatigue is measured with four items from the Three-Dimensional Work Fatigue Inventory [43] mental fatigue subscale. The items are adapted to one-week period. An example item is: "Over the past week, how often did you feel mentally worn out at the end of the workday?". The response scale ranges from 1 (never or almost never) to 5 (very often or all the time).

\section{Stress}

Stress symptoms are measured with a one-item scale adapted from Elo, Leppänen and Jahkola [44]. First, participants indicate whether they have felt stress symptoms over the past week on a scale ranging from 1 (not at all) to 5 (very much). If applicable, participants are asked to specify in which life domain they experienced this kind of stress within the past week. They can indicate this on a scale from 1 (only during off-job time) to 7 (only at work) with the scale's middle point indicating stress both in private and work life.

\section{Health status}

Health status is measured with one item [45]. Participants are asked to assess their current general health status on a scale from 1 (very bad) to 5 (very good).

\section{Private life satisfaction}

Private life satisfaction is measured with a single item adapted from job satisfaction item: "How satisfied have you been with your private life over the past week?". In this context, private life refers to everything outside of work context, including family life, leisure activities, domestic chores, hobbies. Participants are asked to indicate their private life satisfaction on a scale ranging from 1 (very dissatisfied) to 10 (very satisfied). 


\section{Job satisfaction}

Job satisfaction is measured with a single item: "How satisfied have you been with your job over the past week?". A single-item measure has been shown to be acceptable to measure job satisfaction [46]. Participants can indicate their job satisfaction on a scale ranging from 1 (very dissatisfied) to 10 (very satisfied).

\section{Work engagement}

Participants work engagement is assessed with six items from the Utrecht Work Engagement Scale vigor and dedication subscales [47]. The items are adapted to oneweek period. Example items are: "Over the past week at my work, I felt bursting with energy" (vigor) and "Over the past week, I was enthusiastic about my job" (dedication). Participants can choose between seven response options from 0 (never) to 6 (always).

\section{Performance}

\section{Family role performance}

Participants' performance in private life is assessed with a family role performance scale developed by Chen and colleagues [48]. The 4-item subscale measuring relationship performance in one's family life is used in this study. The items are adapted to one-week period. An example of relationship performance item is: "Providing emotional support to your family members". Participants can indicate to what extent their feel that they fulfilled what was expected of them in relation to different aspects of their current family life on a scale from 1 (did not fulfill expectations at all) to 5 (fulfilled expectations completely).

\section{Job performance}

To measure job performance, participants are asked to rate their overall work performance over the past week on a single-item measure [49]. The scale ranges from 1 (the worst job performance a person could have at your job) to 10 (performance of a top worker at your job).

\section{Organizational citizenship behavior}

Organizational citizenship behavior is measured with five items from a scale developed by Lee and Allen [50] and an additional item by Goodman and Svyantek [51]. The first three items measure behaviors directed towards the individuals. An example item is: "You have assisted others with their duties". The next three items measure behaviors directed towards the organization, such as: "You offered ideas to improve the functioning of the organization". Participants are asked how often they have engaged in these behaviors over the past week on a scale from 1 (never) to 7 (always).

\section{Potential moderators, mediators and control variables} Need strengths

Need strengths is measured with the baseline questionnaire. The items are adapted from Chen and colleagues [25]. In the current study, we use one question per dimensions for detachment and relaxation needs and two questions per dimension for autonomy, mastery, meaning, and affiliation needs. Example items are: "It is important to me to mentally disengage from my work during my off-job time" (detachment), "It is important to me to relax after my work is done" (relaxation), "It is important to me to feel in control" (autonomy), "It is important to me to develop my skills and abilities" (mastery), "It is important to me to achieve a sense of purpose in what I am doing" (meaning) and "It is important to me to experience close connections to the people around me" (affiliation). The need strength is measured on a scale from 1 (not important at all) to 5 (very important).

\section{Basic need satisfaction}

Basic need satisfaction is measured with nine items from the Basic Psychological Need Satisfaction and Frustration Scale [25]. The scale is reduced to three items per each psychological need based on the highest factor loadings in the study conducted by Chen and colleagues [25]. The items are adapted to one-week timeframe. Example items are: "Over the past week, I've felt a sense of choice and freedom in the things I undertook" (autonomy), "Over the past week, I've felt capable at what I did" (competence) and "Over the past week, I've felt that the people I care about also cared about me" (relatedness). Participants are asked to respond on a 5-point Likert scale ( 1 = completely untrue, 5 = completely true).

\section{Satisfaction of psychological needs}

DRAMMA needs experiences are measured with a 16item scale. Detachments, relaxation, autonomy and mastery dimensions are each measured with three items from the Recovery Experience Questionnaire [14]. In addition, four additional items were developed to measure meaning and affiliation. Example items are: "Over the past week, during time after work, I forgot about work" (detachment), "Over the past week, during time after work, I kicked back and relaxed" (relaxation), "Over the past week, during time after work, I determined for myself how I will spend my time" (autonomy), "Over the past week, during time after work, I did things that challenge me" (mastery), "Over the past week, during time after work, I experienced meaning in my life" (meaning), "Over the past week, during time after work, I experienced close connections to the people around me" (affiliation). Participants can indicate their agreement with 
the statements on a scale from 1 (I do not agree at all) to 5 (I fully agree).

\section{Home demands}

Home demands are measured with the Home Demands Scale [52]. The scale consists of three subscales: quantitative home demands (example item: "How often have you been busy at home over the past month?"), emotional home demands (example item: "How often did emotional issues arise at home over the past month?" and mental home demands (example item "How often did you have to do many things simultaneously at home over the past week?"). The scale used in this study consists of nine items with one original mental demands item excluded. Participants are asked to report their demands in private life over the past week with the answer range from 1 (never) to 5 (very often).

\section{Job demands}

During each measurement, participants are asked to report their past week's working hours. Additionally, three types of job demands will be measured during each measurement. Workload is measured with three items from the Quantitative Workload Inventory [53]. An example question is: "How often did your job require you to work very fast over the past week?". Cognitive job demands are measured with three questions from the Copenhagen Psychosocial Questionnaire [54] and the DISC Questionnaire [55]. An example item is: "How often did your work require that you remember a lot of things over the past week?". Emotional job demands are measured with three items from the Copenhagen Psychosocial Questionnaire [54]. An example item is: "How often did your work evoke unpleasant feelings over the past week?". The response scales for all job demand items ranges from 1 (very rarely or never) to 5 (very often or all the time).

\section{Job crafting}

Job crafting is measured with a 4-item job crafting scale [56]. An example item is: "I change my job so it would better fit with who I am". Participants are asked to respond on a 5-point Likert scale from 1 (very rarely or never) to 5 (very often).

\section{Off-job activities}

Off-job activities are measured with a newly developed scale. The scale is composed of various scales which have previously been used to measure participation in different leisure activities [57-61]. Participants can indicate the frequency of engaging in different leisure activities (e.g., active socializing, cultural activities, outdoor activities) on a scale from 1 (almost never) to 5 (several times a day).

\section{Proactive personality}

Proactive personality is measured only with the baseline questionnaire, using a six-item version of the Proactive Personality Scale [62]. An example item is: "I excel at identifying opportunities". Employees can choose a response from 1 (totally disagree) to 5 (totally agree).

\section{Focus on opportunities}

Focus on opportunities is measured in the baseline questionnaire with a four-item scale [63]. An example item is: "My occupational future is filled with possibilities". Participants can reply on a scale from 1 (does not apply at all) to 5 (applies completely).

\section{Selection, optimization and compensation strategies}

Selection, Optimization and Compensation strategies are measured in the baseline questionnaire with a twelveitem scale [63]. The scale has four subscales: elective selection (example item: "At work, I concentrate all my energy on few things"), loss-based selection (example item: "When things at work don't go as well as they have in the past, I choose one or two important goals"), optimization (example item: "At work, I make every effort to achieve a given goal"), and compensation (example item: "When things at work don't go as well as they used to, I keep trying other ways until I can achieve the same result I used to"). Participants can reply on a scale from 1 (does not apply at all) to 5 (applies completely).

\section{Background variables}

We ask the participants to state their age, gender, highest level of formal education, family status, living situation, type of work, weekly working hours, and tenure.

\section{Statistical analyses \\ Sample size calculation}

The G*POWER software [64] was used to determine the minimum number of participants necessary to guarantee sufficient power of the study. Assuming an effect size of .25 (medium), alpha $=.05$ and power $=.80$, the required sample size is 64 participants per group to determine a significant difference between the intervention and the waitlist control group. Taking into account potential non-response and loss to follow-up, we aim to recruit at least 200 employees to ensure an adequate sample size.

\section{Basic analyses}

All basic analyses are carried out with SPSS 25 [65]. Two-tailed significance level of $<.05$ will be considered statistically significant. Baseline characteristics of the participants are analyzed using descriptive statistics. Independent samples t-tests or chi-square tests are applied to check whether randomization was successful or 
whether there were systematic differences between the two groups. Preliminary analysis will be performed, including calculating descriptive statistics (i.e., means, standards deviations), factor analyses for all the scales, internal reliability calculations (Cronbach's $\alpha$ ) and bivariate correlations (Pearson's $r$ ) between the study variables.

\section{Effect evaluation}

We will use multilevel modelling techniques to test the change in outcome variables within subjects across seven measurement points before, during and after the intervention (i.e., within subject effect of participating in offjob crafting intervention). We will use Bliese and Ployhart's [66] approach to estimate multilevel models in R, using the NLME library written by Pinheiro and Bates [67]. Additionally, we will test how participation in offjob intervention compared to control group affects the change in outcome variables across time (i.e., between subjects' effect of the intervention compared to control group).

\section{Moderator and mediator analyses}

For moderator and mediator analysis, we will use the nonparametric resampling method of bootstrapping (with 5000 bootstrap resamples) [68]. Hayes' PROCESS macro for SPSS is used to run the bootstrapping procedure. Bootstrapping does not assume the sampling distribution of the indirect effect to be normally distributed, it is statistically more powerful, and is suitable to use on small samples [68].

\section{Process evaluation}

At the end of the second training session, a process evaluation will be conducted to provide insights into the process of the intervention and the mechanisms that might have influenced the effectiveness of the intervention. Participants are asked to indicate the extent that they participated in the intervention, the level of effort invested in following the intervention, and whether they perceived participation in the intervention to be timeconsuming. Additionally, we ask them to report their level on enjoyment and satisfaction with the intervention, relevance of the training content, and the type of perceived support that they received from others during the intervention. We also ask participants to assess whether they gained new skills and knowledge from the intervention, and to express their level of satisfaction with the performance of the trainers during on-site trainings. Regarding the smartphone app Everydaily, we ask participants to indicate how many Dailys they have completed and whether they also logged all the completed Dailys to the app to gain better understanding about participants' app use. Regarding off-job crafting goal setting, participants are asked to indicate the psychological need that they worked on during the intervention period and write down the goal that they set during the first training session. They are then asked to rate their goal attainment during the intervention period on a scale from 0 to $100 \%$. Finally, participants can describe the most important things that they learned during the intervention and provide any additional comments.

\section{Discussion}

This article describes the development and design of a hybrid off-job crafting intervention study aimed at enhancing employees' off-job crafting behaviors, psychological needs satisfaction, well-being and performance.

\section{Strengths and limitations}

The main limitation of the study is that the intervention includes several on- and offline components. With the two-armed randomized control trial (intervention versus waitlist control), it is not possible to evaluate each specific component separately, and it is therefore difficult to establish which intervention components are the most effective. However, we aim to conduct a thorough process evaluation to gain insights into recruitment, reach, fidelity, participants' attitudes toward the intervention, context, implementation, dose delivered and dose received, and to link the effect and process evaluation results to better understand the different mechanisms that might have influenced the effectiveness of the intervention [34]. Secondly, as the intervention and the waitlist control group participants are recruited from the same organization and potentially form the same departments, contamination may occur. While the trainings, booklets and smartphone app are first only made available for the intervention group, there is still a chance that colleagues participating in the intervention could share their training materials with the waitlist control group participants. To minimize this risk, intervention participants are specifically reminded not to share the training materials with the control group members until the end of the intervention period. Thirdly, another limitation might be participants' non-adherence to the instructions or dropping out of the study entirely. In order to avoid these potential complications, we will explain the procedures to the participants carefully both in the informed consent form and during the first training session to remind participants about the importance of following the entire intervention program. We will also send them a mid-intervention postcard reminder and will monitor closely the weekly questionnaire response rates, sending reminders to those who do not fill out the questionnaires by the deadlines indicated in the emails. 
We will further assess adherence to the intervention program with the process evaluation.

To the best of our knowledge, this is the first intervention study to evaluate the effectiveness of a hybrid offjob crafting intervention to enhance off-job crafting behaviors, psychological needs satisfaction, well-being and performance in different life domains. The study has direct practical implications for employees and their wellbeing. Participation in the trainings, following an individual off-job crafting plan, and using the smartphone app could potentially offer a brief and accessible way for employees to increase their off-job crafting behaviors, which in turn could enhance psychological needs satisfaction, well-being and performance in different life domains. Besides potential benefits for the employees, the intervention could also benefit the organizations, potentially resulting in healthier and more productive employees. Finally, the intervention content allows plenty of room for customization to meet each participant's individual psychological needs, and can therefore be offered to workers from different professions, educational levels and life situations.

\section{Acknowledgements}

We thank the two trainers Anu Kervinen and Anna Maria Sirenius for their support in developing the content of the intervention. Moreover, we thank Markus Domin for programming the Everydaily app.

\section{Authors' contributions}

MK wrote the manuscript. FR and JdB conceptualized the research project. $\mathrm{JdB}$ secured funding for the project. MvdH advised the authors on research design and the development of the intervention content. All authors read and approved the final manuscript.

\section{Funding}

This research project is supported by the Academy of Finland (grant nr. 308718). The funding received by the Academy of Finland has been used to develop the smartphone app and cover travel expenses of the researchers and their collaborators.

\section{Availability of data and materials}

Data will be shared after completion of the research project in the Finnish Social Science Data Archive. Data and intervention materials are also available on request from the first author.

\section{Ethics approval and consent to participate}

The Ethics Committee of the Tampere Region has approved the study (statement 46/2019). A written informed consent is obtained from each participant.

\section{Consent for publication}

Not applicable.

\section{Competing interests}

The authors declare that they have no competing interests.

\section{Author details}

'Department of HRM \& OB, Faculty of Economics and Business, University of Groningen, Nettelbosje 2, 9747, AE, Groningen, the Netherlands. ${ }^{2}$ School of Social Sciences, Tampere University, Kalevantie 5, 33100 Tampere, Finland. ${ }^{3}$ Department of Work and Organizational Psychology, University of Amsterdam, Nieuwe Achtergracht 129B, 1018, WS, Amsterdam, The Netherlands.
Received: 13 January 2020 Accepted: 15 January 2020

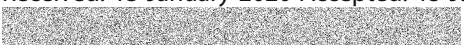

\section{References}

1. Eurofound. Sixth European Working Conditions Survey - Overview report (2017 update). Luxembourg; 2017. https://doi.org/10.2806/784968.

2. Schaufeli WB, Bakker AB. Job demands, job resources, and their relationship with burnout and engagement: a multi-sample study. J Organ Behav. 2004; 25:293-315.

3. Bakker A, Demerouti E, Schaufeli W. Dual processes at work in a call Centre: an application of the job demands - resources model. Eur J Work Organ Psy. 2003;12:393-417.

4. Sturges J. Crafting a balance between work and home. Hum Relat. 2012;65: 1539-59.

5. De Bloom J, Kinnunen U, Korpela K. Recovery processes during and after work: associations with health, work engagement, and job performance. J Occup Environ Med. 2015;57:732-42.

6. Tims M, Bakker AB. Job crafting: towards a new model of individual job redesign. SA J Ind Psychol. 2010;36:1-9. https://doi.org/10.4102/sajip.v36i2. 841.

7. van Wingerden J, Bakker AB, Derks D. Fostering employee well-being via a job crafting intervention. J Vocat Behav. 2017;100:164-74. https://doi.org/10. 1016/j.jvb.2017.03.008.

8. Berg JM, Grant AM, Johnson V. When callings are calling: crafting work and leisure in pursuit of unanswered occupational callings. Organ Sci. 2010;21: 973-94. https://doi.org/10.1287/orsc.1090.0497.

9. Petrou $P$, Bakker AB. Crafting one's leisure time in response to high job strain. Hum Relat. 2016;69:507-29.

10. Meijman TF, Mulder G. Psychological aspects of workload. In: Drenth PJD, Thierry $\mathrm{H}$, de Wolff $\mathrm{CJ}$, editors. Handbook of work and organizational psychology. 2nd ed. Hove: Psychology Press; 1998. p. 5-33.

11. Deci EL, Ryan RM. The "what" and "why" of goal pursuits : human needs and the delf-determination of behavior. Psychol Inq. 2000;11:227-68.

12. Baard PP, Deci EL, Ryan RM. Intrinsic need satisfaction: a motivational basis of performance and well-being in two work settings. J Appl Soc Psychol. 2004;34:2045-68. https://doi.org/10.1111/j.1559-1816.2004.tb02690.x.

13. Newman DB, Tay L, Diener E. Leisure and subjective well-being: a model of psychological mechanisms as mediating factors. J Happiness Stud. 2014;15: $555-78$.

14. Sonnentag S, Fritz C. The recovery experience questionnaire: development and validation of a measure for assessing recuperation and unwinding from work. J Occup Health Psychol. 2007;12:204-21.

15. Ryan RM, Deci EL. Self-determination theory and the facilitation of intrinsic motivation, social development, and well-being. Am Psychol. 2000;55:68-78.

16. Iwasaki Y. Pathways to meaning-making through leisure-like pursuits in global contexts. J Leis Res. 2008;40:231-49.

17. Edwards JR, Rothbard NP. Mechanisms linking work and family: clarifying the relationship between work and family constructs. Acad Manage Rev. 2000;25:178-99.

18. Bartholomew LK, Parcel GS, Kok G, Gottlieb NH, Fernandez ME. Planning health promotion program: an intervention mapping approach. 3rd ed. San Francisco, CA: Jossey-Bass; 2011.

19. Ropponen A, Bergbom B, Härmä M, Sallinen M. Asiantuntijatyön työajat yhteydet työhön ja hyvinvointiin; 2018.

20. Toivanen M, Yli-Kaitala K, Viljanen O, Väänänen A, Turpeinen M, Janhonen M, et al. AikaJärjestys asiantuntijatyössä. 2016.

21. Salmela-Aro K, Upadyaya K. Role of demands-resources in work engagement and burnout in different career stages. J Vocat Behav. 2018; 108:190-200. https://doi.org/10.1016/j.jvb.2018.08.002.

22. van den Heuvel M, Demerouti E, Peeters MCW. The job crafting intervention: effects on job resources, self-efficacy, and affective well-being. J Occup Organ Psychol. 2015;88:511-32. https://doi.org/10.1111/joop.12128.

23. Kinnunen U, Feldt T, Siltaloppi M, Sonnentag S. Job demands-resources model in the context of recovery: testing recovery experiences as mediators. Eur J Work Organ Psy. 2011;20:805-32.

24. Kujanpää M, Syrek C, Kinnunen U, Mäkikangas A, Tay L, Brauchli R, et al. A needs-based off-job crafting scale: cross-cultural and cross-domain validation of a new instrument. Manuscript under revision 2019.

25. Chen B, Vansteenkiste M, Beyers W, Boone L, Deci EL, Van der Kaap-Deeder $J$, et al. Basic psychological need satisfaction, need frustration, and need strength across four cultures. Motiv Emot. 2015;39:216-36. 
26. Ashforth BE, Kreiner GE, Fugate M. All in a day's work: boundaries and micro role transitions. Acad Manage Rev. 2000;25:472-91.

27. Hayes SC, Luoma JB, Bond FW, Masuda A, Lillis J. Acceptance and commitment therapy: model, processes and outcomes. Behav Res Ther. 2006:44:1-25.

28. Bandura A. Self-efficacy: toward a unifying theory of behavioural change. Psychol Rev. 1977;84:191-215.

29. Kashdan TB, Blalock DV, Young KC, Machell KA, Monfort SS, McKnight PE, et al. Personality strengths in romantic relationships: measuring perceptions of benefits and costs and their impact on personal and relational wellbeing. Psychol Assess. 2018;30:241-58.

30. Sandstrom GM, Dunn EW. Social interactions and well-being: the surprising power of weak ties. Pers Soc Psychol Bull. 2014;40:910-22.

31. Doran TG. There's a S.M.A.R.T. way to write management's goals and objectives. Manag Rev (Ama Forum). 1981;70:35-6.

32. Sheldon KM, Niemiec CP. It's not just the amount that counts: balanced need satisfaction also affects well-being. J Pers Soc Psychol. 2006:91:331-41.

33. Gollwitzer PM. Goal achievement: the role of intentions. Eur Rev Soc Psychol. 1993:4:141-85.

34. Murta SG, Sanderson K, Oldenburg B. Process evaluation in occupational stress management programs: a systematic review. Am J Health Promot. 2007;21:248-54.

35. Kaplan S. The restorative benefits of nature: toward an integrative framework. J Environ Psychol. 1995;15:169-82. https://doi.org/10.1016/02724944(95)90001-2.

36. Jacobson E. The technic of progressive relaxation. J Nerv Ment Dis. 1924;60: 568-78.

37. Babouchkina A, Robbins SJ. Reducing negative mood through mandala creation: a randomized controlled trial. Art Ther. 2015;32:34-9.

38. Bolier L, Haverman M, Westerhof GJ, Riper H, Smit F, Bohlmeijer E. Positive psychology interventions: a meta-analysis of randomized controlled studies. BMC Public Health. 2013:13:119.

39. Richardson KM, Rothstein HR. Effects of occupational stress management intervention programs: a meta-analysis. J Occup Health Psychol. 2008;13:6993.

40. Sin NL, Lyubomirsky S. Enhancing well-being and alleviating depressive symptoms with positive psychology interventions: a practice-friendly metaanalysis. J Clin Psychol. 2009:65:467-87.

41. Hood M, Bostic TJ, Rubio DM. A validation of the subjective vitality scale using structural equation modeling. Soc Indic Res. 2000;52:313-24.

42. Ryan RM, Frederick C. On energy, personality, and health: subjective vitality as a dynamic reflection of well-being. J Pers. 1997;65:529-65.

43. Frone MR, Tidwell M-CO. The meaning and measurement of work fatigue: development and evaluation of the three-dimensional work fatique inventory (3D-WFI). J Occup Health Psychol. 2015;20:273-88.

44. Elo A-L, Leppanen A, Jahkola A. Validity of a single-item measure of stress symptoms. Scand J Work Environ Health. 2003;29:444-51.

45. Wu S, Wang R, Zhao Y, Ma X, Wu M, Yan X, et al. The relationship between self-rated health and objective health status: a population-based study. BMC Public Health. 2013;13:320.

46. Wanous JP, Reichers AE, Hudy MJ. Overall job satisfaction: how good are single versus multiple-item measures? J Appl Psychol. 1997;82:247-52.

47. Schaufeli WB, Bakker AB, Salanova M. Short UWES. Educ Psychol Meas. 2006; 66:701-16.

48. Chen Y-P, Shaffer M, Westman M, Chen S, Lazarova M, Reiche S. Family role performance: scale development and validation. Appl Psychol. 2014;63:190218.

49. Kessler RC, Barber C, Beck A, Berglund P, Cleary PD, McKenas D, et al. The World Health Organization health and work performance questionnaire (HPQ). J Occup Environ Med. 2003;45:156-74.

50. Lee K, Allen NJ. Organizational citizenship behavior and workplace deviance: the role of affect and cognitions. J Appl Psychol. 2002;87:131-42.

51. Goodman SA, Svyantek DJ. Person-organization fit and contextual performance: do shared values matter. J Vocat Behav. 1999;55:254-75.

52. Peeters MCW, Montgomery AJ, Bakker AB, Schaufeli WB. Balancing work and home: how job and home demands are related to burnout. Int J Stress Manag. 2005;12:43-61.

53. Spector PE, Jex SM. Development of four self-report measures of job stressors and strain: interpersonal conflict at work scale, organizational constraints scale, quantitative workload inventory, and physical symptoms inventory. J Occup Health Psychol. 1998;3:356-67.
54. Pejtersen JH, Kristensen TS, Borg V, Bjorner JB. The second version of the Copenhagen psychosocial questionnaire. Scand J Public Health. 2010;38:824. https://doi.org/10.1177/1403494809349858.

55. De Jonge J, Dormann C, Van Vegchel N, Von Nordheim T, Dollard M, Cotton S, et al. The DISC Questionnaire, English version 2.1. 2007.

56. Vanbelle E, Van den Broeck A, De Witte H. Job crafting: Autonomy and workload as antecedents and the willingness to continue working until retirement age as a positive outcome. Psihol Resur Um. 2017;15:25-41. https://doi.org/10.24837/pru.2017.1.3.

57. Brajša-Žganec A, Merkaš M, Šverko I. Quality of life and leisure activities: how do leisure activities contribute to subjective well-being? Soc Indic Res. 2011;102:81-91

58. Demerouti $E$, Bakker AB, Geurts $S A E$, Taris TW. Daily recovery from workrelated effort during non-work time. Res Occup Stress Well Being. 2009;7: $85-123$

59. Eldredge BD, Tinsley HEA. Psychological benefits of leisure participation: a taxonomy of leisure activities based on their need-gratifying properties. J Couns Psychol. 1995;42:123-32

60. Official Statistics of Finland (OSF): Participation in leisure activities [epublication]. 2006. http://www.stat.fi/til/vpa/tau_en.html.

61. Vauhkonen A. Virkistääkö vapaa-aika? Vapaa-ajan toimintojen koettu virkistävyys ja niihin käytetty aika suomalaisilla. Tampereen yliopisto; 2010. http://urn.fi/urn:nbn:fi:uta-1-20987.

62. Claes R, Beheydt C, Lemmens B. Unidimensionality of abbreviated Proactive Personality Scales across cultures. Appl Psychol. 2005;54:476-89.

63. Zacher $\mathrm{H}$, Frese M. Maintaining a focus on opportunities at work: the interplay between age, job complexity, and the use of selection, optimization, and compensation strategies. J Organ Behav. 2011;32:291-318.

64. Faul F, Erdfelder E, Lang A-G, Buchner A. G*power 3: a flexible statistical power analysis program for the social, behavioral, and biomedical sciences. Behav Res Methods. 2007:39:175-91.

65. IBM SPSS Statistics for Windows, Version 25.0. 2017.

66. Bliese PD, Ployhart RE. Growth modeling using random coefficient models: model building, testing, and illustrations. Organ Res Methods. 2002;5:36287.

67. Pinheiro JC, Bates DM. Mixed effects models in S and S-PLUS. New York: Springer; 2000.

68. Preacher KJ, Hayes AF. SPSS and SAS procedures for estimating indirect effects in simple mediation models. Behav Res Methods Instrum Comput. 2004:36:717-31.

\section{Publisher's Note}

Springer Nature remains neutral with regard to jurisdictional claims in published maps and institutional affiliations.

Ready to submit your research? Choose BMC and benefit from:

- fast, convenient online submission

- thorough peer review by experienced researchers in your field

- rapid publication on acceptance

- support for research data, including large and complex data types

- gold Open Access which fosters wider collaboration and increased citations

- maximum visibility for your research: over $100 \mathrm{M}$ website views per year

At BMC, research is always in progress.

Learn more biomedcentral.com/submissions 